\title{
EL CONCEPTO KANTIANO DE UNIVERSALIZACIÓN Y SU FECUNDIDAD PARA LA TEORÍA MORAL
}

Graciela Hierro

Facultad de FILOSOFfa y Letras Universidad Nacional autónoma de México

Deseo iniciar este artículo planteando la pregunta kantiana que no es tan familiar: "¿Cómo es posible la ética normativa?" En otras palabras: "¿Es posible enunciar y defender racionalmente una ética normativa, de tal manera que todas las personas racionales — después de una reflexión cuidadosa- puedan encontrarla aceptable?"

El propósito de la ética normativa, también llamada teoría moral, es el de establecer sistemáticamente el principio o los principios generales para determinar lo recto y lo obligatorio. ${ }^{1}$ En este trabajo intento formular los prolegómenos de una teoría de la obligación moral, a partir de la idea kantiana de 'universalización', para una ética del interés. En esa forma intentaré resolver el conflicto aparente entre el interés y el deber.

La teoría de la obligación de Kant recibe el título general de deontología ("deon" deber, "logos" ciencia). Una teoría deontológica sostiene que hay por lo menos un tipo de actos que son moralmente obligatorios, independientemente de sus consecuencias. El primer filósofo que enuncia el principio deontológico, en forma sistemática, es precisamente Manuel Kant; de acuerdo con él, el comportamiento objetivamente recto puede ser inspirado por la prudencia, por la benevolencia, por el respeto a la ley moral, o por otro tipo de motivos. Sin embargo, el único que permite alcanzar el rango de moral es el comportamiento que surge del resepeto por la ley moral. La regla moral es universalmente válida y no admite excepción alguna. ${ }^{2}$

El concepto de 'universalización' que permite reconocer la obligación

I Conviene distinguir lo "recto" de lo "obligatorio". Los actos rectos son los actos aprobados moralmente. Los actos obligatorios son aquellos que producen mayor bien que cualquiera de las alternativas abiertas para el agente moral, en una situación dada. Hay actos rectos que, sin embargo, no constituye nuestro deber realizarlos. Por ejemplo, es un acto recto contraer matrimonio con la persona amada, sin embargo, puede pensarse que no constituye nuestro deber hacerlo.

2 Kant, M., Fundamentación de la Metafísica de las Costumbres (FMC). 
moral —en los términos que veremos más adelante- es, a mi juicio, la aportación central del filósofo de Königsberg a la teoría moral. La preocupación en este trabajo es mostrar lo fructífero de este concepto de universalización, en particular para las doctrinas éticas utilitarias, que tradicionalmente se han considerado antagónicas al formalismo kantiano. ${ }^{3}$

En la actualidad existe un gran número de autores utilitarios que favorecen una versión modificada de la ética deontológica. El utilitarismo de la regla es el punto de vista que sostiene que toda regla moral debe ser justificada mostrando que su adopción generalizada tiene consecuencias humanamente deseables.

En las dos versiones deontológicas, el formalismo kantiano y el utilitaxismo de la regla, se pretende dar respuesta a la pregunta que plantea Cicerón en De Officci, cuando el filósofo estoico busca, según su propia confesión, una regla principal que resuelva el conflicto - aparenteentre el deber, entendido como la obligación absoluta de actuar de cierta manera, y el interés, planteado como la felicidad del agente. ${ }^{4}$

Finalmente, es interesante recordar que Cicerón expone la enseñanza estoica a través de tres ideas principales: a) La idea de la ley de la naturaleza. $b$ ) La idea del ser humano como valiosa y merecedora de respeto, sólo por el hecho de ser humano, y $c$ ) la idea de una sociedad universal de seres racionales. ${ }^{5}$ Todas estas consideraciones son las que emplea Kant para la obtención de su criterio de la obligación moral: el imperativo categórico.

El texto de Kant que utilizo para este trabajo es la Fundamentación de la metafísica de las costumbres* (FMC); en la argumentación sigo el siguiente orden:

Primero señalo, en términos generales, lo que se entiende por obligación moral, específicamente la perspectiva deontológica y la teleológica.

En segundo lugar caracterizo, en base al texto kantiano, el imperativo categórico y su prueba de la universalidad. Presento algunas consideraciones relevantes para comprender el concepto de universalidad para mostrar su asimilación al concepto de obligación.

En tercer y último lugar, señalo una aplicación del concepto de uni-

3 El sentido corriente de "utilitarismo" es la idea de que "los predicados morales de un acto - por lo menos su bondad o maldad objetiva, y algunas veces también sus posibilidades de alabanza o censura - son funciones, de alguna manera directa $o$ indirecta, de las consecuencias del acto para el bienestar de los seres vivos y sólo de esto". Brandt, R., "Towards...", en: Utilitarianism..., p. 324.

4 Cicero, On the Good Life. De Officci: I, II, III.

5 Ibid. Grant, M., "Introduction".

* Kant, M., Fundamentación de la metafisica de las costumbres. Editora Espasa Calpe, Argentina, 1946. 
versalidad para la ética utilitaria y apunto a la integración de este concepto en un tipo de utilitarismo de la regla que llamo: "Etica del Interés".

\section{Las teorias de la obligación moral}

Se dice que tenemos obligación moral de actuar de cierta manera, cuando se considera que cierto tipo de actos son necesarios moralmente, independientemente de sus consecuencias. Se discute, sin embargo, si puede plantearse que estos actos sean siempre obligatorios. ${ }^{6}$

Por otra parte, Kant sostiene la unidad entre deber y leyes morales; a este respecto, el filósofo alemán explica que la moralidad requiere que se actúe de acuerdo con una máxima que pueda ser considerada como una ley universal que no admite excepciones. ${ }^{\text {? }}$

Si bien todas las teorías de la obligación moral se presentan como guías para las decisiones y los juicios acerca de los actos morales, en la actualidad se habla de dos tipos de teorias. Las teleológicas señalan como criterio básico de la rectitud de las acciones el valor que producen como consecuencia. El juicio último sobre las acciones recae, directa o indirectamente, sobre la cantidad comparativa de bien que producen, o en el balance comparativo de bien sobre el mal resultante. De tal modo un acto es recto si y sólo si la regla bajo la cual cae su cumplimiento produce -o probablemente producirá- por lo menos un mayor balance de bien sobre el mal que cualquier alternativa posible. ${ }^{8}$ Por tanto produce, o probablemente producirá, menos mal que cualquier alternativa posible.

Las teorías deontológicas niegan Io que las teolológicas afirman. Niegan que lo recto, lo obligatorio y lo moralmente bueno sea totalmente en función directa $o$ indirecta de lo que es bueno no moralmente: felicidad o placer. Sostienen que existen por lo menos otras consideraciones que pueden hacer a una acción o a una regla, recta u obligatoria. ${ }^{9}$ Las consideraciones pueden ser ciertos rasgos del acto mismo, además del valor que produce. Por ejemplo, se puede pensar que los actos son obli-

6 Las teorías éticas generalmente proponen condiciones de validación para las obligaciones morales. Por ejemplo: salud mental, cierta madurez, no ser ateo, en el caso de las éticas religiosas, etc.

7 Kant, M., FMC, p. 40.

8 Frankena, W. F., Ethics, p. 13.

9 Las teorías deontológicas pueden ser del acto o de la regla. Las primeras sostienen que los juicios básicos de obligación son particulares, es decir: "En esta situación se debe hacer $x$." Los deontólogos de la regla piensan que el criterio de lo recto consiste en una o más reglas. Por ejemplo, "se debe cumplir el principio de la justicia". Frankena, W. F., Ethics, p. 15. 
gatorios por ser mandatos divinos, independientemente de las consecuencias que produzcan para la felicidad del agente, o para la felicidad general.

\section{La prueba de Kant para la obligación moral}

En la $F M C$ el interés de Kant se concentra en el análisis de un tipo particular de enunciado ético: los enunciados acerca del deber o de la obligación. Su tesis es relevante para este tipo de enunciados; esto no limita de ninguna manera el valor de la teoría kantiana, puesto que la fundamentación de los enunciados acerca de la obligación es el problema más importante de la teoría moral, como advierte Kant mismo. ${ }^{10}$ A continuación formulo, en líneas generales, los puntos principales de la perspectiva kantiana sobre la obligación moral.

\section{A. El imperativo categórico}

En el prólogo de la $F M C$ Kant nos indica la finalidad de lo que él llama la "metafísica de las costumbres", es decir, un sistema de conocimiento a priori, libre de los elementos empíricos, propio de una discusión de la parte puramente racional de la ética. Lo anterior con el intento de encontrar la norma suprema para enjuiciar las costumbres, ya que éstas - a su juicio- están expuestas a toda suerte de corrupción en el conocimiento vulgar que mezcla los principios puros del entendimiento con los empíricos. ${ }^{11}$

De esta manera pretende Kant llevar a cabo la distinción tajante entre el deber y el interés, eliminando la subjetividad de la problemática moral.

En el Capítulo I de la $F M C$, nos ofrece Kant, de modo dramático, la primera proposición de la moralidad: "Ni en el mundo, ni en general tampoco fuera del mundo es posible pensar nada que pueda considerarse como bueno sin restricciones, a no ser tan sólo una buena voluntad." 12

Más adelante Kant introduce el concepto de deber como el medio para determinar la naturaleza de la buena voluntad. La noción primera

io Comenta Kant en la FMC que... "la presente fundamentación no es más que la investigación y asiento del principio supremo de la moralidad... esa cuestión im. portantísima y hasta hoy no dilucidada". El mismo propósito persigue John $\mathrm{S}$. Mill en el Utilitarismo cuando advierte "el escaso progreso conseguido en la solución de la controversia relativa al criterio del bien y el mal".

11 Kant, M., FMC, p. 16.

12 Ibid., p. 27. 
del deber, para una buena voluntad humana, es decir, para que una acción posea valor moral, es el hecho de que la motivación de la acción sea el deber mismo y no la inclinación. ${ }^{13}$

"Una acción hecha por deber tiene su valor moral, no en el propósito que por medio de ella se quiere alcanzar (es decir, la finalidad que se desea), sino en la máxima por la cual ha sido resuelta." ${ }^{44}$ Esta máxima no es otra que el imperativo categórico, que es el enunciado de deber u obligación moral. Vemos pues que el valor moral reside en el principio de la voluntad como principio puro: "El deber es la necesidad de una acción por respeto a la ley moral." ${ }^{15}$ Es por ello que a lo único que puede llamarse bueno, sin restricciones, es a la buena voluntad cuya motivación es el respeto a la ley moral (la ley de la libertad), que es esencialmente universal.

La referencia universal que entraña el imperativo categórico se expresa diciendo, en palabras kantianas: "Yo no debo obrar nunca más que de modo que pueda querer que mi máxima deba convertirse en ley universal." 16

De este único imperativo categórico pueden derivarse, como de su principio, todos los imperativos del deber. ${ }^{17} \mathrm{El}$ imperativo en cuestión representa la legalidad que puede ser usada como criterio práctico moral - para asegurarnos de que nuestra voluntad, cuando la ejercemos con la motivación debida- es moralmente buena.

La ley moral también se utiliza para la comprensión de lo que es la moralidad. En efecto, Duncan sostiene que en la $F M C$ el establecimiento de la ley moral persigue un doble objetivo: Primero, la descripción del funcionamiento de la moralidad en los seres humanos concretos. Segundo, como principio prescriptivo, es decir como guía de la conducta, ${ }^{18}$ al mostrar la forma en que la razón práctica se desempeña. $\mathrm{O}$ sea, cómo —de hecho- a juicio de Kant razonan prácticamente los agentes morales cuando se ven enfrentados a un conflicto moral.

Por ejemplo, en el caso de decidir acerca de si se debe o no cumplir una promesa contraída, cuando el hecho de hacerlo traiga consigo consecuencias indeseables para la felicidad del agente. Se responde a esto formulando la norma de las promesas (el deber subjetivo de cumplirlas) que existe en la moral de las sociedades. Al ser yo un agente moral autónomo, convierto la máxima subjetiva: "Debo cumplir la promesa",

13 Ibid., p. 25.

14 Ibid., p. 37.

15 Ibid. p. 39.

16 Ibid. p. 71.

17 Ibid. p. 72.

18 Duncan, A. R. C., Practical Reason and Morality, p. 31. 
en una máxima universalizada: "Se deben cumplir las promesas", independientemente de las consecuencias; y en ese momento adquiero la obligación moral de cumplirla, al convertir la máxima en ley.

\section{B. La universalización}

Hemos visto cómo para Kant los sujetos morales guían su acción a través de máximas. Estas máximas son subjetivas y cuando el sujeto las universaliza, es decir, las torna válidas para todo sujeto racional, adquieren necesidad y objetividad. Es por ello que la máxima subjetiva es en realidad una ley moral de la libertad, una vez que el sujeto descubre que son prescritas por la razón. En ese sentido, el método que utiliza Kant para determinar el principio de la moral, es intuitivo. Éste es, a juicio de Sidgwick, el término que denota la perspectiva ética que contempla, como el fin último de la acción moral, su conformidad con ciertas reglas o dictados del deber, prescrita incondicionalmente. En estos términos, "intuición" significa: "un juicio inmediato de lo que debe de ser o a lo que se debe apuntar". Intuitivo se traduce en lenguaje kantiano por a priori. ${ }^{19}$

La universalización de la máxima es el principio moral de Kant para guiar la conducta. Constituye el fundamento de la ética normativa, o sea su condición de posibilidad. A continuación veamos, en forma somera, el énfasis del principio universalizado. Nos dice Kant, en la $F M C$, que todas las máximas tienen:

1. Una forma que consiste en la universalidad y, en este sentido, se expresa la fórmula del imperativo moral.

2. Una materia, esto es, un fin, y entonces dice la fórmula que el ser racional debe servir como fin por su naturaleza $y$, por tanto, como fin en sí mismo.

3. Una determinación integral de todas las máximas por medio de aquella fórmula, a saber, que todas las máximas, por propia legislación deben concordar en un reino posible de fines, como un reino de la naturaleza. ${ }^{20}$

El argumento anterior da por supuesto, primero, que toda la actividad voluntaria humana —en lo moral- se realiza en función de máximas determinadas a priori, es decir, racionalmente, sin que intervenga un proceso de razonamiento, conocidas en un acto mental inmediato. Asimismo, supone que los fines individuales - mediando la razón - se conjugan en un fin último: la humanidad, que es un fin en sí mismo.

Es por ello que puede decirse, según Kant, que la razón fundamenta 19 Sidgwick, H., The Methods of Ethics, pp. 211 ss.

20 Kant, M., FMC, p. 94. 
a la moral. Efectivamente, no se trata en la universalización de la máxima - de acuerdo con Kant- que se proceda a revisar críticamente todas las máxmas bajo las cuales se actúa, sino que la experiencia moral está sujeta a la concordancia de los fines de la acción humana, y éste es el sentido profundo de la universalización kantiana. Aun cuando el individuo entre en conflicto con el grupo, o aun on el caso de que cl individuo se encuentre aislado, se confirma su pertenencia a la "sociedad universal de seres racionales", como sostiene Cicerón. La idea de universalización no es otra que la idea de obligación, tan pronto como se interpreta "universalidad" como pertenencia constitutiva del individuo a la comunidad de los seres racionales, y por este hecho mantiene obligaciones con la comunidad humana real. En ese momento, inclusive la obligación del individuo frente a sí mismo se torna en una exigencia, ya no propiamente suya, sino compartida con todos sus congéneres. Oigamos lo anterior en palabras de Kant: "Los fines del sujeto, que es él mismo un fin, deben ser necesariamente mis fines, si la representación de la Humanidad como un fin en sí misma tiene toda su determinación en mí." 21

Paton, en su penetrante estudio del imperativo categórico, aclara el sentido de universalización en la forma siguiente:

La universalidad es la característica esencial de la ley como tal. Una ley de la naturaleza debe valer para todos los eventos temporales sin excepción... la ley de la libertad... es la ley de acuerdo con la cual todos los seres racionales actuarían si la razón ejerciera un control absoluto sobre sus inclinaciones.

Por otra parte, continúa Paton, la universalidad del deber es un hecho familiar para la conciencia moral. Es decir, si hay algo que sea "la moralidad" debe haber un criterio moral objetivo, válido para todos los agentes morales, independientemente de sus deseos y fines particulares. ${ }^{22}$ La forma de la ley moral, en síntesis, es la universalidad, la materia, todas las máximas que expresan nuestras inclinaciones, la razón $a$ priori, nos permite conocer nuestra obligación moral, universalizando la máxima subjetiva y conciliando así los intereses personales y sociales.

La máxima universalizada tiene una función reguladora y controla. dora de la conducta, como vimos. Sin embargo, no agota en esa función su valor y fecundidad. La universalización requiere también el apoyo de la sabiduría personal y del compromiso moral al utilizar la razón para

21 Sidgwick, H., op. cit, cita a Kant FMC, p. 59.

22 Paton, H. J., The Categorical Imperative, pp. 69 ss. 
guiar la acción y aceptar la prescriptividad de la regla. La máxima da cuenta del valor de una persona y para muchos esto constituye precisamente la medida de la dignidad humana.

\section{El utilitarismo}

A continuación señalo brevemente lo fructifera que resulta la aplicación del principio kantiano de la universalización al utilitarismo. Como ya apunté antes, entiendo esta teoría como la doctrina que sostiene la rectitud de las acciones en función de la bondad o maldad de sus consecuencias. Sin embargo, en muchos casos puede plantearse que la obligación moral de actuar de cierta manera se sostiene independientemente de las consecuencias del acto en cuestión, en circunstancias determinadas. ¿Cómo resolver entonces este problema utilizando únicamente el criterio teleológico de la obligación moral? Veamos un ejemplo: Mentir a un enfermo grave acerca de su condición puede traer como consecuencia mayor bien (menor sufrimiento para el enfermo) que si se le informa la verdad acerca de su salud; sin embargo, puede pensarse que se debe decir la verdad aun a costa de causarle mayor sufrimiento, por considerar que se tiene la obligación moral de hacerlo. Lo obligatorio posee mayor fuerza moral que lo conveniente en este caso. Pero, ¿cuáles serían las razones para apoyar la decisión? Pienso que precisamente la posibilidad de universalizar la regla; el considerar que la moralidad de una acción particular se reconoce por la aplicación de una ley, y que la ley es recta si y sólo si sus consecuencias son útiles, es decir, promueven el bien o evitan el mal general, tal como plantea el utilitarismo de la regla. En efecto, el valor de los actos que se consideran obligatorios, en una perspectiva utilitaria de la regla, puede ser enunciado como sigue: "Hay ciertos actos que de ser realizados en un número ' $n$ ' de ocasiones similares tienen consecuencias más de ' $n$ ' veces mejores que las resultantes de realizarse una sola vez. $\mathrm{Y}$ estos actos son los que se llaman moralmente obligatorios." 23

Son éstos los actos cuya generalización trae como consecuencia un balance más favorable, en cuanto a los resultados, que los que se desprenden de la realización de uno solo de estos actos. Por ejemplo: Para que el otro obtenga privilegios yo debo ceder algunos de los míos, y eso contribuye a mi felicidad si y sólo si todos los hacen. En una sociedad de tolerantes se es más feliz que en una donde sólo unos cuantos son tole-

23 Harrod, R. F., "Utilitarianism Revised", p. 81. 
rantes. En una sociedad de intolerantes el tolerante es el "insensato", como señala Hobbes.

Para Kant, como vimos, la aprobación del principio de la obligación se hace en función de la intuición. Constituye para el filósofo una necesidad lógica para evitar la contradicción dentro de la conducta del sujeto moral que se guía por la razón. Fn el utilitarismo de la regla se acepta la obligación desde otro fundamento: porque constituye su interés hacerlo; es decir, se acepta la prescriptividad en función de las ventajas de su adopción general. La teoría moral utilitaria integra, en esa forma, tanto los sentimientos personales (interés) como el juicio de la razón (deber). Se consigue así superar el utilitarismo que plantea la obligación moral únicamente en función de lo 'conveniente' (expediency) que posee escasa fuerza obligatoria; $y$, por otra parte, se supera el formalismo kantiano que -al parecer- se desentiende del interés humano.

Generalmente se piensa que las teorías deontológicas de la obligación entran en contradicción con la filosofía de los fines. Sin embargo, este conflicto es sólo aparente; en el utilitarismo de la regla, como he querido mostrar, se considera la obligación moral de cumplir con ciertas reglas -en función del interés humano- que, sin embargo, se sostienen moralmente, independientemente de sus consecuencias inmediatas sobre la felicidad o el sufrimiento del agente.

\section{A. La teoria de la obligación de la ética del interés}

En esta doctrina se sostiene la obligación moral de cumplir las reglas, es decir, las máximas universalizadas, para garantizar el interés aun cuando su cumplimiento no traiga consigo consecuencias favorables inmediatas.

El conflicto que puede existir entre el interés individual y el deber se resuelve en dos etapas: En primera instancia, el agente se pregunta si existe una regla aceptada que requiera o prohíba el acto propuesto. ${ }^{24}$ La segunda etapa consiste en preguntarse si esta regla universalizada, es decir, obligatoria aun cuando sus consecuencias no sean favorables, pro-

24 Stuart Hamsphire, en Two Theories of Morality, propone la clasificación de las teorias morales en dos tipos:

De acuerdo con la relación que guarden con las opiniones morales establecidas; las primeras explican estas opiniones como especificaciones de principios más generales. (El utilitarismo propone el principio de la utilidad como el fundamento de la moralidad del sentido común.) Las segundas muestran el camino para una conversión moral. (La Ética de Spinoza sería un ejemplo de este segundo caso.) 
mueve la felicidad general en mayor medida que si se cumple (o no se cumple) esporádicamente. Si éste es el caso, entonces constituye nuestra obligación moral universalizar la regla y aceptar su prescriptividad, independientemente de las consecuencias inmediatas. ${ }^{25}$

Corresponde este tipo de decisiones a lo que tradicionalmente se conoce como los "deberes penosos"; es decir, cuyo cumplimiento trae consecuencias indeseables inmediatas, pero que, sin embargo, es nuestra obligación moral cumplirlos. Esto, no por el empeño de evitar la contradicción en nuestra conducta y actuar como seres racionales; en verdad se trata de prever las consecuencias indeseables (o deseables) de una máxima universalizada para garantizar mejor el interés, es decir, la felicidad general, y éste es el criterio para determinar su obligatoriedad.

Por ejemplo, el amor propio puede incitarnos a mentir para salvar nuestra reputación, en el caso de haber cometido un acto considerado indeseable por nuestra comunidad; sin embargo, si se universalizara esta práctica esto traería consigo consecuencias desastrosas para la comunidad por la probable pérdida de confianza, aunque la mentira pueda traer consecuencias inmediatas favorables para el agente. En la perspectiva utilitaria corriente - al parecer- el acto recto, juzgando las consecuencias inmediatas, sería recurrir a la mentira; sin embargo, el utilitarista de la regla consideraría su obligación moral universalizar la regla de la veracidad, cuyo cumplimiento generalizado contribuye en mayor medida al interés, que calculando las consecuencias - de mentir o no mentiren un acto particular.

\section{Conclusiones}

Todo el planteamiento anterior puede ser sintetizado en los siguientes puntos:

1. La ética normativa pretende establecer el principio o los principios generales para determinar el deber. Es decir, formular una teoría de la obligación moral.

2. Las teorías de la obligación moral son: deontológicas, cuando sostienen que hay por lo menos un tipo de actos que son moralmente obligatorios independientemente de sus consecuencias; teleológicas cuandr. sostienen que la rectitud de los actos se reconoce en función del valor que producen sus consecuencias. Hay dos variantes dentro de las teorías deontológicas: la intuitiva y la del interés.

3. La prueba de Kant para la obligación moral es intuitiva. La regla

25. Atkinson llama "deliberativo" al primer momento de la decisión moral y al segundo "veredictivo"; una vez que se ha elegido la regla a seguir. (Atkinson, R. F., La conducta. UNAM, México, 1981, p. 20.) 
se universaliza y toma la forma de la obligación, su materia son los intereses humanos y supone la integración de todas las leyes en una sola: la ley universal de la libertad.

4. Para Kant, la razón fundamenta a la moral en su capacidad de propiciar o inhibir comportamientos al universalizar las máximas y tornarlas en leyes. La universalidad se identifica con la obligatoriedad.

5. El concepto de universalidad u obligación es la contribución más importante de Kant a la teoría moral. Permite superar la aparente contradicción entre el interés y el deber.

6. Se garantiza el interés al universalizar aquella máxima cuyos resultados son mejores que realizar esos mismos actos en forma esporádica, y esto constituye nuestro deber.

Intuicionismo y utilitarismo de la regla, dos soluciones al problema de Cicerón para resolver el conflicto entre el interés y el deber.

\section{BIBLIOGRAFIA}

Atkinson, R. F. La conducta. UNAM, México, 1981.

Brandt, R. G., "Some Merits of one Form of Rule Utilitarianism". En: Utilitarianism with Critical Essays. The Bobbs-Merrill Co., Inc. USA, 1971.

Cicero, On the Good Life. Penguin Classics, Australia, 1971.

Duncan A. R. C. Practical Reason and Morality. Thomas Nelson \& Sons. Toronto, 1957.

Frankena W. F. Ethics. Prentice-Hall, Inc. U.S.A. s/f.

Hampshire, Stuart. Two Theories of Morality. Oxford University Press. U. K., 1967.

Harrold, R. F., "Utilitarianism Revised", en: Utilitarianism with Critical Essays. Op. cit.

Kant, M. Fundamentación de la metafísica de las costumbres. Ed. Espasa-Calpe Argentina, Buenos Aires, 1946 (Col. Austral).

Paton, H. J. The Categorical Imperative. Harper Torchbooks, U.S.A., 1967.

Sidgwick, H. The Methods of Ethics. Dover Pub., Inc. New York, 1966. 